\title{
Learner Participation in School Governance: The Views of Learner Governors in South African Schools
}

\author{
Dr M. A. N. Duma \\ University of Zululand, KwaDlangezwa . 3886, Republic of South Africa. \\ Email:dumam@unizulu.ac.za
}

Doi:10.5901/mjss.2014.v5n20p1807

\begin{abstract}
This article explores the view of learner governors in school management in South Africa. The South African Schools Act No. 84 of 1996 stipulates that all public secondary schools in South Africa must have democratically elected Representative Councils of Learners (RCL). This Act was intended to foster collective decision-making in schools. Apart from a literature review on learner management, empirical study investigation based on quantitative research paradigm was used to collect data from learner governors on their role in school management. The findings highlighted the important functions of learner governors in schools and it is concluded by the submission that it is essential for schools to build the necessary frameworks and communication avenues for developing learner governors.
\end{abstract}

Keywords: collective decision -making; distributed leadership; learner governors; learner management.

\section{Introduction}

After 1994, the South African government introduced several education policies and legislations to democratise school management. The most important Act was passed in 1996, known as the South African Schools Act (SASA). Through this Act, democratic school management structures were established in all public schools (Carr, 2005). This democratisation included the idea that learners have to participate in the school governance (Mabena, 2002). SASA prescribes that all public secondary schools in South Africa must establish school governing bodies (SGBs) and the learners must have their representatives in these SGBs (Karlsson, 2002). In addition, each secondary school has to establish a Representative Council of Learners (RCL), elected by learners (South Africa, 1996).

It is not easy to dispute the benefits that learner governors can have for school management activities, yet learner governors and principals often hold one another at arm's length, unsure of the role that each should play in school management. Some principals love to have learner governors involved in school management, while others feel that too much learner governors' involvement in school management compromises their sense of professionalism.

Duma (2013) asserts that the absence of learner experience from school management brings about the systematic silencing of the learner's voice, whereas learner governors enhance and promote school democratic practices.

\section{Literature Review}

\subsection{Conceptualising learner governorship in schools}

There is a considerable amount of international and comparative literature on democratic education which includes the many arguments supporting it, yet very little research has been conducted on the role of learner governors in school management. The relative unavailability of literature on this research problem is itself an indication that research has to be done in order to provide more insight and improved approaches to this issue.

A great deal of literature both nationally and internationally supports the need for greater democracy in schools. Mncube (2009) confirms that this literature suggests that listening to learners, encouraging their participation and giving them more power and responsibility leads to a better functioning school. This contention is supported by Chapman, Froumin and Aspin (1995) as they argued that a democratic society grows from the roots provided by a democratic school system and, therefore, if a society wants to make itself free, it should give more freedom to schools.

The conceptual underpinning of learner governorship is premised on the distributed leadership theory. Spillane, Halverson and Diamond (2004) define distributed leadership as a theory of leadership practice. It is a leadership 
approach in which collaborative working is undertaken between individuals who trust and respect each other's contribution, occurring as a result of an open culture within and across an institution. Scott McLeod (2012) further on astutely points out that that distributed leadership is an approach in which reflective practice is an integral part enabling actions to be critiqued, challenged and developed through cycles of planning, action, reflection and assessment. It happens most effectively when people at all levels engage in action, accepting leadership in their particular areas of expertise. In this instance, learner leadership is thought critical to innovation in school management.

\subsection{The history of learner governorship in South Africa}

O'Connell (1991) contends that the role of learner governors in school management has always been at the centre of the struggle for educational transformation in South Africa. It is therefore important to understand where learner governorship had its origins, and the role it played in the creation of the new South Africa.

Before 1980, a culmination of a number of factors in Soweto led to the establishment of the Soweto Students Representative Council (SSRC), which spearheaded the dropping of Afrikaans as a medium of teaching and learning (Brooks and Brickhill, 1980). On 16 June 1976, learners marched through Soweto and the police opened fire at them, killing a thirteen-year-old boy, Hector Peterson (Sithole, 1995).

After 1980, the Reconstruction and Development Programme advocated that in the field of education and training, structures of institutional governance which reflect the interest of all stakeholders and the broader community served by the institution should be established (ANC, 1994). This led to the formation of the Congress of South African Students (COSAS). The formation of the National Education Crisis Committee (NECC) in 1986 was probably the most significant milestone in the democratisation of education. What it did, was to bring together a large number of actors within the educational sphere, and representing all stakeholders (NEPI, 1992).

The Educational Renewal Strategy (ERS) document and the National Education Policy Investigation (NEPI) both advocated increased learner participation in school governance through the policy of educational decentralization ( NEPI,1992). In order to establish the principle of greater responsibility among the community for school education, management councils were established in schools in which learners were given an observer status (NEPI, 1992). The ANC Policy Framework for Education and Training, propagated a balance between the responsibilities of national and provincial government and popular participation in policy development and implementation through structures of governance and consultation (Zafar, 1999).

The 1995 Hunter Report confirmed the participation of learners in school management as it stipulated that the composition of school governing bodies should comprise parents, teachers and learners (Hunter, 1995). In 1996, the South African Schools Act legalised learner participation in school management, as it stated that a Representative Council of Learners at school must be established at every public school enrolling learners in grade eight and higher ( South Africa,1996).

\section{Research Methodology}

To address the research problem, both literature study and empirical investigation based on quantitative research design were undertaken. The researcher consulted literature which is relevant to the topic. This was done to provide a critical synthesis of what has already been written on the topic.

\subsection{Quantitative Research Paradigm}

A survey to gather questionnaire-based data in a real-life setting was used in the study. The research design included the delimitation of the field of survey, the selection of respondents (size of the sample and sampling procedures), the research instruments, namely the questionnaires, a pilot study, the administration of the questionnaires, and the processing of data.

\subsection{Population and Sampling}

The researcher used the simple random sampling method to select two hundred leaner governors from Ugu district schools. This method was favoured for its simplicity, unbiased nature, and its closeness to fulfilling the major assumption of probability, namely that each element in the population stands an equal chance of being selected (Kumar, 2010). For ethical reasons, permission to conduct research in schools was sought from the relevant district office. 


\subsection{Instrumentation}

The questionnaire was used as research instrument. This quantitative methodology was chosen in the light of the purpose of the study, the kind of information that was required and the available resources. As McMillan, Schumacher (2006) and Kumar (2010) maintain that questionnaires permit anonymity, preclude possible interviewer biases and permit a respondent sufficient time to consider answers before actually answering. Data provided by questionnaires can be more easily analysed and interpreted than the data obtained from verbal responses and lastly, questionnaires can elicit information that cannot be obtained in other methods. The researcher believed that this kind of survey would lead to some truths about the role of learner governorship in secondary schools and it would provide information on whether certain generalisations presented in the literature were also true for this population.

\subsection{Format of the Questionnaire}

The questionnaire was divided into four sections, with each section focusing on the aims of the study. Section 1 consisted of questions, which focus on the biographic and general information. This section provided the researcher with an understanding and knowledge of the respondents. Section 2 had closed questions focusing on views held by learner governors on their role in school management. The respondents were asked to rate their responses according to the following scale: Strongly Agree, Agree, Disagree, and Strongly Disagree. Section 3 consisted of open-ended questions, wherein respondents were asked to write down the problems they encounter in school management. Sections 4 consisted also of open-ended questions, wherein learner governors had to suggest ways that can improve their performance in schools.

\subsection{Administration of the Questionnaires}

The researcher conducted a pilot study in six schools in Ugu district. The schools were part of the general population from which the sample was drawn, but not part of the sample itself. No inherent weaknesses were discovered in the questionnaires and the data solicited confirmed the questionnaires' validity and reliability, consequently there was no need to modify the questionnaires.

In the actual study, 200 learner governors were requested to complete their questionnaires which were later posted to the researcher, using the self addressed envelope supplied with the questionnaire.

The first sample population responses were 140 (70\%) respondents. After the follow-ups, 15 respondents returned the completed questionnaires to make total of 155 responses (76\%). That represented a satisfying response.

\subsection{Data Processing}

After all the questionnaires had been received, the important task was then to reduce the mass of data obtained to a format suitable for analysis. The respondents' responses were coded and frequency distributions were generated.

\section{Findings and Discussion}

\subsection{General and Biographical profile of the Respondents}

When the item of learner governors' education background was analysed, it was realised that all the respondents had fully completed the information regarding general and biographical data.

Table 1. Education background of learner governors

\begin{tabular}{|c|c|c|}
\hline Education background of learner governors & $\mathbf{N}$ & $\%$ \\
\hline Grade 8 & 0 & 0 \\
\hline Grade 9 & 0 & 0 \\
\hline Grade 10 & 20 & 13 \\
\hline Grade 11 & 34 & 22 \\
\hline Grade 12 & 101 & 65 \\
\hline Total & 155 & 100 \\
\hline
\end{tabular}


This table provided the researcher with knowledge of the education background of the learner governors. $155(n=155)$ responded. Table 1 revealed that more than half of the respondents (65\%) had standard 10 (Grade 12) that confirmed the assertion that the education level of learner governors was improving. Success in the execution of the learner governors' duties including learner management is determined by the extent to which the learner governors are educated.

\subsection{Learner governors' views on their role in rural school management}

Table 2. Learner governors' views on their role in rural school management

\begin{tabular}{|c|c|c|c|c|c|c|}
\hline Items & & Strongly Agree & Agree & Disagree & Strongly Disagree & Total \\
\hline \multirow{2}{*}{$\begin{array}{l}\text { Learner governors should focus on achieving effective } \\
\text { educational and social outcomes for learners }\end{array}$} & $\mathrm{N}$ & 31 & 62 & 32 & 28 & 155 \\
\hline & $\%$ & 20 & 41 & 21 & 18 & 100 \\
\hline \multirow{2}{*}{$\begin{array}{l}\text { Learner governors should base their operations on the } \\
\text { premises of inclusion }\end{array}$} & $\mathrm{N}$ & 23 & 70 & 47 & 15 & 155 \\
\hline & $\%$ & 14 & 45 & 30 & 10 & 100 \\
\hline \multirow{2}{*}{ Learner governors should be nominated by teachers } & $\mathrm{N}$ & 23 & 70 & 47 & 15 & 155 \\
\hline & $\%$ & 14 & 45 & 30 & 10 & 100 \\
\hline \multirow{2}{*}{$\begin{array}{l}\text { Learner governors should be responsive to changing } \\
\text { school expectations }\end{array}$} & $\mathrm{N}$ & 62 & 71 & 15 & 7 & 155 \\
\hline & $\%$ & 40 & 46 & 10 & 4 & 100 \\
\hline \multirow{2}{*}{$\begin{array}{l}\text { Learner governors should foster closer ties between } \\
\text { learners and teachers }\end{array}$} & $\mathrm{N}$ & 116 & 19 & 15 & 5 & 155 \\
\hline & $\%$ & 75 & 12 & 10 & 3 & 100 \\
\hline \multirow{2}{*}{$\begin{array}{l}\text { Learner governors should contribute to the identity } \\
\text { and development of learner personalities }\end{array}$} & $\mathrm{N}$ & 22 & 113 & 11 & 9 & 155 \\
\hline & $\%$ & 14 & 73 & 7 & 6 & 100 \\
\hline \multirow{2}{*}{$\begin{array}{l}\text { Learner governors should expose learners to differing, } \\
\text { diverse, and conflicting viewpoints }\end{array}$} & $\mathrm{N}$ & 22 & 113 & 11 & 9 & 155 \\
\hline & $\%$ & 14 & 73 & 7 & 6 & 100 \\
\hline
\end{tabular}

Table 2 presents information related to the views held by learner governors on their role in school management. The respondents were asked to rate their responses according to the following scale: Strongly agree, Agree, Disagree and strongly disagree.

Learner governors should focus on achieving effective educational and social outcomes for learners. Table 2 revealed that more than half of the respondents (61\%) indicated that they agreed with the statement that learner governors should focus on achieving effective educational and social outcomes for learners. This high percentage confirms the importance of learner governors in schools since learner leaders need to focus on the individual learning, psychological, social, and emotional needs of each learner. Learner governorship programmes should prepare learner leaders who can facilitate the creation of effective learning environments.

Learner governors should base their operation on the premises of inclusion. As it is shown in Table 2, the majority of the respondents (70\%) agreed that learner governors should base their operation on the premises of inclusion. This high percentage of respondents once again confirms that the primary emphasis of schooling should be to effectuate the full potential of learners. The complexities of the increasingly diverse and economically-stratified society mandate that all learner governors to be skilled educational leaders that understand the fine balance between responsiveness to community expectations and advocacy for current successful practices. Learner governorship programmes should produce learner governors who can facilitate the inclusion and success of all learners, regardless of sex, colour, social class and disability, sexual orientation, etc.

Learner governors should be nominated by teachers. Table 2 further on revealed that more than half of the respondents (60\%) indicated that they agreed that teachers should nominate learner governors. This is against the dictates of the South African Schools Act and the stipulations of the Provincial Gazette Extraordinary (5946), dated 31 January 2003 which both asseverate that the composition of a Representative Council of Learners should consist learner elected representatives.

Learner governors should be responsive to changing school expectations. As it is shown in Table 2, a high proportion of the respondents (86\%) agreed that learner governors should be responsive to changing expectations while simultaneously affirming the numerous, daily successes that currently occur in schools. This is confirmed by Scott McLeod (2012), when he avers that skilled learner leaders understand the fine balance between responsiveness to political and community expectations and advocacy for current successful practices. Learner management programmes should prepare leaders who understand the political, economic, and cultural contexts surrounding education and who are proficient communicators with their teachers.

Learner governors should foster closer ties between learners and teachers. Table 2 revealed that more than half of 
the respondents $(87 \%)$ indicated that learner governors should foster closer ties between teachers and learners. The main objective of establishing the learner governors in schools is to create a sense of co-responsibility. It is also an attempt to create a sound and healthy relationship between learners, teachers and non-teachers, as well as parents. This implies that most respondents understand the importance of learner governors in fostering closer ties between teachers and learners in school management activities. Participation of learners governors in school management, as required by the South African Schools Act is based on the concept that learners as members of the school community have a right to participate in decision-making processes.

Learner governors should contribute to the identity and development of learner personalities.

Table 2 revealed that a high proportion of the respondents (90\%) indicated that learner governors should contribute to the identity and development of learner personalities. Learner governorship enhances the personality development. Learners involved in leadership do not to sit towards the back of class due to phobias and psychological illnesses. Their attitudes vacillate from the ability to collaborate with others and manifest positive views about life.

Learner governors should expose learners to differing, diverse, and conflicting viewpoints. In conclusion, Table 2 revealed a majority of the respondents (87\%) indicated that learner governors should facilitate the discussion of conflicting viewpoints. In learner governorship there is an acknowledgement of the varying views which makes consensus possible. The airing of differences and open engagement in exploring assorted opinions and perspectives tends to lead to an appreciation of the strength that diversity can yield. Open conversation allows people to put aside suspicions that arise when conflicting views are cloaked in false consensus. Whitney and Trosten-Bloom (2010) support this contention as they pointed out that the process of engaging with the conflicts rather than suppressing them somewhat paradoxically enables the organisation to focus on the "higher good" and execute sustainable strategies more successfully.

\subsection{Problems encountered by learner governors in school management}

In an open-ended question, learner governors were required to mention the problems they encounter in school management. Their responses, ranked in the order of frequency, were as follows:

- Teachers do not support leaner governors in the performance of their duties (78\%)

- Teachers interfere with leaner governors' school management activities (75\%)

- Teachers do not regularly interact with learner governors (68\%)

- Teachers undermine learner governors (66\%)

- Teachers lack understanding of the role of learner governors in school management activities (60\%).

\section{Concluding Remarks}

The study has revealed that learner governors in South Africa still experience problems in school management, despite the establishment of the South African Schools Act, which mandates all schools to have learners participating in school management (South Africa, 2003). In conclusion, the study recommended that schools should build the necessary frameworks and communication avenues for developing learner governorship and establish special programmes focused on learner governorship.

\section{References}

African National Congress (1994). The Reconstruction and Development Programme: a Policy Framework. Johannesburg: Umnyano Publishers.

Brooks, A, \& Brickhill J ( 1980). Whirlwind Before the Storm: Origins and Development of the Uprising in Soweto and the Rest of South Africa from June to December 1976. London: International Defence and Aid Fund for South Africa

Carr I A ( 2005). From Policy too Praxis: A Study of the Implementation of Representative Councils of Learners in the Western Cape. Ph.D.Thesis. Unpublished. Cape Town: University of Western Cape. 2005)

Chapman J D, Froumin D \& Aspin D (1995). Creating and Managing the Democratic School. London: Falmer Press.

Duma M.A.N. (2013). The principals' views on parent participation in governance of rural schools (2013). Studies on Home and Community Science 7(2): 99-107

Hunter A P (1995). Report of the Committee to Review the Organization, Governance and Funding of Schools. Pretoria: DoE.

Karlsson J (2002). The role of democratic governing bodies in South African schools Comparative Education, 38 (3): 327-336.

Kumar, R. (2010). Research Methodology: As Step-by-Step Guide for Beginners. New Delhi: SAGE Publications.

Mabena L T 2002. Learner Involvement in School Governance as an Aspect of School Management: Implication for Whole School Development. Masters Thesis, Johannesburg: Rand Afrikaans University. 
McMillan J,\& Schumacher S (2006). Research in Education: Evidence-Based Inquiry. Boston: Allyn and Bacon.

Mncube V (2009). Perceptions of the principal's role in democratic school governance in South Africa .Journal of Educational Administration and History, 41(1): 29-43

National Education Policy Investigation Report (1992). Governance and Administration Research Group (NEPI). Cape Town: Oxford University Press.

O'Connell B (1991). Education and transformation: a view from the ground, in: Unterhalter E, Wolpe H, Botha T, Badat S, Dlamini T, Khotseng, B. (eds.), Apartheid Education and Popular Struggles. Johannesburg: Ravan Press, 31: 131-145.

Scott McLeod J D (2012). Urban Educational Leadership Program University of Cincinnati. Cincinnati, Ohio http://homepages.uc.edu/ mcleodst/ > Retrieved November 29, 2013.11.29

Sithole S (1995). The Participation of Students in Democratic School Governance in Democratic Governance of Public Schooling in South Africa: a Record of Research and Advocacy. Durban: University of Natal.

South Africa (1996). South African Schools Act, 1996. Pretoria: Government gazette No. 17579.

South Africa (2003). Extraordinary Provincial Gazette 2003. Pretoria: Extraordinary Provincial Gazette 5946

Spillane J P, Halverson R \& Diamond J B (2004). Towards a Theory of leadership practice: a distributed perspective, Journal of Curriculum Studies, 36:1, 3-34,

Whitney D, \& Trosten-Bloom A( 2010). The Power of Appreciative Inquiry: A Practical Guide to Positive Change, 2nd Edition, San Francisco: Berrett-Koehler Publishers

Zafar, S. (1999). Statutory Governance Councils. Education Monitor, 10(1):1-8. Durban: University of Natal: Education Policy Unit. 